\title{
ALGIRDAS JULIEN GREIMAS E ROLAND BARTHES: SEMELHANÇAS E DIFERENÇAS ENTRE A SEMIÓTICA E A SEMIOLOGIA \\ ALGIRDAS JULIEN GREIMAS AND ROLAND BARTHES: SIMILARITIES AND DIFFERENCES BETWEEN SEMIOTICS AND SEMIOLOGY
}

\author{
Marcos Rogério Martins COSTA ${ }^{1}$ \\ Universidade de São Paulo/USP \\ marcosrmcosta15@gmail.com \\ Patrícia Margarida Farias COELHO 2 \\ Universidade Metodista de São Paulo/UMESP \\ patriciafariascoelho@gmail.com
}

RESUMO: Este artigo aborda a relação desses dois grandes pensadores do século XX, Algirdas Julien Greimas (1917-1992) e Roland Barthes (1915-1980), que desenvolveram os estudos pioneiros sobre o nível transfrástico da língua. 0 objetivo é discutir as pesquisas de Barthes e de Greimas com o intuito de apreender as convergências e divergências que acolhem e separam esses dois pensadores revolucionários do campo das ciências humanas. Como metodologia, este estudo tem caráter exploratório, com fundamentação bibliográfica nas pesquisas desses autores. Para a análise bibliográfica, dividimos este artigo em duas partes, a saber: (1) o contexto histórico em que estão inseridos esses dois pesquisadores; e (2) as semelhanças e as diferenças dos estudos semióticos e semiológicos. Como resultado, este estudo aponta as relevantes e diferentes perspectivas desses autores no cenário dos estudos do texto e discurso.

Palavras-chave: semiótica; semiologia; estruturalismo.

ABSTRACT: Algidas Julien Greimas and Roland Barthes : similarities and differences between semiotics and semiology - This article discusses the relationship between these two great thinkers of the twentieth century, Algirdas Julien Greimas (1917-1992) and Roland Barthes (1915-1980), who developed the pioneering studies on the level beyond sentence in the language. The objective is to discuss the semiotic researches of Barthes and Greimas in order to apprehend the convergences and the divergences that join and separate these two thinkers revolutionaries of the field of human sciences. As a methodology, this study has an exploratory character, with a bibliographic basis in the researches of these authors. For the bibliographic analysis, we divide this article into two parts, namely: (1) the historical context in which these two researchers are inserted; and (2) the similarities and differences of semiotic and semiological studies. As a result, this study points out the relevant and different perspectives of these authors in the context of text and discourse studies.

Keywords: semiotics; semiology; structuralism.

\section{Introdução}

A semiologia é uma ciência das formas, visto que estuda as significações, independentemente do seu conteúdo. Gostaria de dizer uma palavra sobre a necessidade e os limites desta ciência formal (BARTHES, 2003, p. 202).

Se, no sentido, o termo semiótica serve para designar um conjunto significante anteriormente à sua descrição, numa nova acepção, ele é

\footnotetext{
1 Doutorando do Programa de Pós-Graduação em Semiótica e Linguística Geral da Universidade São Paulo (USP). Professor efetivo da Secretaria Municipal de Educação de São Paulo.

2 Professora Doutora Titular no Programa de Pós-Graduação em Educação na Universidade Metodista de São Paulo (UMESP) e Pós-doutoranda na Pós-Graduação em Educação: Currículo da Pontifícia Universidade Católica de São Paulo - PUC-SP.
} 
empregado para denominar um objeto de conhecimento em via de constituição: tratar-se-á, então, de uma semiótica-objeto considerada quer como projeto de descrição, quer como já submetida à análise, quer, enfim, como objeto construído. Por outras palavras, não se pode falar de semiótica, a não ser quando existe encontro entre a semiótica-objeto e a teoria semiótica que a aprende, enforma e articula (GREIMAS; COURTÉS, 2008, p. 450).

A Antiga Grécia, com Platão, Aristóteles e os estoicos, foi a responsável por estabelecer a principal diferença entre o semeion (tradução livre, por "natureza significante") e symbolon (a grosso modo, remetia aos "símbolos da cultura"). As duas interpretações desses termos deram origem a onomasiologia que é a ciência que cuida dos nomes e a semasiologia que a ciência que apura os significados das palavras. Mais tarde, Santo Agostinho (354 - 430) foi um dos primeiros a propor uma teoria geral dos signos linguísticos, a qual foi retomada por John Locke (16321704). Com o desenvolvimento das artes médicas e das ciências da saúde, nasce a semiologia que investiga os vestígios das doenças. O sentido da semiologia vai se espraiar para outros campos de estudo, chegando às ciências humanas e da linguagem. É a partir desse recorte que retomamos a semiologia e a comparamos com outra disciplina, a semiótica.

A primeira epígrafe deste artigo traz à tona a interpretação de Roland Barthes (1915-1980). A segunda é de Algirdas Julien Greimas (1917-1992). Cada um desses autores constrói um sentido para essa ciência da significação que, desde os gregos antigos, está em discussão. Do lado de Barthes, temos a semiologia que estuda a significação independentemente do seu conteúdo. Do lado de Greimas, temos a semiótica que examina a significação pelo parecer do sentido (cf. COELHO; COSTA, FONTANARI, 2016), isto é, cada objeto de significação vai ser uma semiótica-objeto que, por sua vez, será submetido a uma análise que não deixa de ser uma semiótica-método, porque nunca é absoluta e única, é um dos efeitos de sentido depreendido pelo investigador, no caso o semioticista. Neste estudo, vamos explorar as semelhanças e as diferenças desses dois vieses.

Tanto Barthes quanto Greimas beberam da mesma fonte primária: os estudos do pai da linguística moderna Ferdinand de Saussure (1857-1913). Conforme Dosse (1993), a principal obra de referência do surgimento da semiologia nas ciências da linguagem foi o Curso de linguística geral, que é um livro póstumo, feito a partir de anotações dos alunos dos cursos ministrados pelo 
mestre suíço em 1907, 1908, 1910 na Universidade de Genebra³ ${ }^{3}$ Nesse livro, na qual a autoria é atribuída à Saussure, reflete-se sobre a necessidade de uma ciência anterior e mais ampla do que a linguística:

Pode-se, então, conceber uma ciência que estude a vida dos signos no seio da vida social; ela constituiria uma parte da Psicologia social e, por conseguinte, da Psicologia geral; chamá-la-emos de Semiologia (do grego semêîon, "signo"). Ela nos ensinará em que consistem os signos, que leis os regem. Como tal ciência não existe ainda, não se pode dizer o que será; ela tem direito, porém, à existência; seu lugar está determinado de antemão. A Linguística não é senão uma parte dessa ciência geral; as leis que a Semiologia descobrir serão aplicadas à Linguística, e esta se achará dessarte vinculada a um domínio bem definido no conjunto dos fatos humanos (SAUSSURE, 2013, p. 47-48, grifos do autor).

Enquanto a Linguística alcança rápida adesão e difusão já no final da década de 1920, no leste europeu, a semiologia teve de esperar cerca de meio século para ser reconhecida como uma disciplina e/ou área do conhecimento. Foi nomeada, ora por Semiótica, pelos seguidores de Greimas, ou por Semiologia, pelos partidários dos estudos de Barthes. Essa dupla nomeação ocorre pela disputa de pontos de vista durante a sua formação, como se pode observar no contexto histórico que se desenvolveu na segunda metade do século XX, principalmente no ato da primeira associação internacional:

A primeira associação internacional de estudos dessa natureza, fundada em 1969, em Paris, adota o termo "semiótica", definindo oficialmente uma escolha que iria tornar-se de uso corrente, inclusive em língua francesa.

Entretanto, enquanto se tentava ultrapassar a questão terminológica, permanecia o distanciamento entre as pesquisas semióticas francesa e americana. Essa separação dicotômica se revelaria, com o tempo, simplista. Os estudos semióticos na verdade se pluralizam cada vez mais, mantendo-se em desenvolvimento constante em diversos países da Europa e da América, relacionando-se a vários outros campos de conhecimento, não só linguísticos como não linguísticos. Isso permitiu a construção, por exemplo, de zoossemióticas, de ecossemióticas, de Semiótica da Música, de uma Semiótica do Gosto, de uma Semiótica das Artes Visuais, e de tantas outras (NOVA; PAULINO, 2009, p. 9).

Esse pluralismo que acompanha os estudos semióticos é evidente quando comparamos dois teóricos de uma mesma época. Para constatar essa afirmação, selecionamos duas importantes figuras desse período de surgimento da disciplina vislumbrada pelo mestre genebrino: Barthes e Greimas.

\footnotetext{
${ }^{3}$ Somente mais tarde, foram encontrados os manuscritos de Saussure e então publicados por Simon Bouquet e Rudolf Haeckel (cf. SAUSSURE, 2002).
} 
Os dois pensadores possuem suas pesquisas bem afinadas com os desdobramentos do nível transfrástico da língua, fomentados principalmente na segunda metade do século XX. Em 1948, Greimas defendeu a sua tese em lexicologia histórica intitulada La mode en 1830. Nesse estudo, o lituano fez uma verdadeira enciclopédia da moda francesa, analisando aspectos estéticos, sociais e econômicos que exerciam domínio e influência no uso dos vocábulos referentes ao campo da moda. Uniu-se, assim, a lexicologia à história, surgindo, portanto, um desdobramento pioneiro no estudo das unidades da língua. Segundo Broden (1998), "esse estudo representa um elo intelectual crucial entre a lexicologia histórica e o Le système de la mode, de Roland Barthes".

Isso fica mais patente se compararmos as publicações desses teóricos na segunda metade do século XX. Em 1966, Greimas publicou Semântica estrutural, obra seminal dos estudos semióticos. Em 1967, Barthes lançou O sistema da moda, trabalho de referência na pesquisa estrutural do vestuário feminino. Temos, assim, dois estudos quase que concomitantes perscrutando as possibilidades da língua(gem) para além do nível da frase: seja no estudo da semântica, como fez Greimas, seja no estudo do sistema da moda, como produziu Barthes.

Observando esse entrelaçamento teórico, é pertinente e justificável compreendermos as semelhanças e as diferenças que acercam esses dois teóricos, principalmente quando se completou o centenário de nascimento de Barthes em 2015; em 2016, o cinquentenário da publicação de Semântica estrutural; e em 2017, o centenário de nascimento de Greimas. Desse modo, esta pesquisa tem o objetivo de abordar os estudos semióticos de Greimas e de Barthes com o intuito de apreender as convergências e divergências que acolhem e separam esses dois pensadores revolucionários do campo das ciências humanas. Esses autores produziram teorias que, quando correlacionadas, podem se complementar, ou se afrontar, a depender do ponto de vista adotado. Sendo assim, é pertinente compreendermos as semelhanças e as diferenças que acercam esses dois teóricos.

Para tanto, dividimos este estudo em duas partes, a saber: (1) o contexto histórico em que estão inseridos esses dois pesquisadores; e (2) as semelhanças e as diferenças dos estudos semióticos e semiológicos. A escolha por essa organização se deve à própria especificidade do fenômeno que estamos analisando: o surgimento dos estudos do texto e do discurso na segunda metade do 
século XX. Justifica-se o interesse por esse período histórico-social e cultural porque as contribuições teóricas e técnicas que ali emergiram fundamentaram as principais correntes científicas contemporâneas, por exemplo, a análise do discurso de linha francesa, a semiótica discursiva e tensiva, a semiologia barthesiana, dentre outras.

\section{0 contexto estruturalista: Saussure, Barthes e Greimas}

Barthes e Greimas repetem temas e crenças, tais como determinação do signo linguístico, apontamento de atrasos e antecipações das teorias do texto e do discurso e reinvindicação de uma postura científica nos estudos da língua(gem). Com isso, eles, cada um a seu modo, atribuem a autonomia de um objeto nas ciências humanas a partir de uma positividade teórica e metodológica, possibilitando uma análise sistemática de tudo o que circunda e emerge de um ato linguístico. A despeito do reconhecimento de suas conquistas científicas, tanto a semiótica greimasiana quanto a semiologia barthesiana parecem ter realçado a fundação e a filiação à perspectiva saussuriana, a qual, por sua vez, instaura e propaga um paradigma científico, ou seja, o estruturalismo.

Ressaltamos que os termos estrutura e estruturalismo não são encontrados na obra seminal Curso de linguística geral. Essa nomenclatura foi efetivamente criada por Roman Jakobson (1896-1982). Ele associou esses termos ao posicionamento saussuriano pela primeira vez no I Congresso Internacional de Linguística em Haia, na Holanda, em 1928.

Segundo Fiorin (1999) e Broden (2011), foi graças a Greimas que Barthes conheceu a obra do linguista dinamarquês Louis Hjelmslev (1899-1965). A partir desse contato com a leitura da obra Prolegômenos para uma teoria da linguagem, de Hjelmslev (2009), publicada pela primeira vez em 1943, Barthes e Greimas ficaram profundamente motivados com o projeto científico ali proposto. De acordo com Fiorin (2003), nesse projeto, o linguista dinamarquês fazia as seguintes escolhas epistemológicas:

Esse projeto teórico visa a compreender o fenômeno da linguagem em si mesmo, faz da compreensão da linguagem um fim em si mesmo. Um tratamento científico do fenômeno linguístico permitiria, segundo Hjelmslev, um patamar homogêneo de comparação das línguas e possibilitaria o estabelecimento de uma linguística genética racional. Em seus Prolegômenos, o linguista dinamarquês procura estabelecer as bases de uma teoria da linguagem. Diante do desconhecimento da 
linguagem em si mesma, é legítimo propor um objeto teórico que busque entendê-la. Hjelmslev nega radicalmente a tradição linguística anterior. Para ele, o único teórico que merece ser tratado como pioneiro é Ferdinand de Saussure (FIORIN, 2003, p. 21).

À sua maneira, tanto Greimas quanto Barthes contribuíram efetivamente para o desenvolvimento do estruturalismo na França, principalmente entre os anos 1950 e 1960. Nesse período, Barthes tornou-se uma das principais figuras do movimento estruturalista. Segundo o semiólogo francês, o estruturalismo é uma atividade que tem por objetivo reconstituir um objeto. Desse modo, o estruturalismo caracteriza-se como um método rigoroso que permitiu o progresso da ciência, pois possibilitou uma releitura e compreensão do objeto analisado para além de seu caráter material.

Como estamos observando, a corrente estruturalista tem como ponto unificador o nome de Saussure. Assim, gostaríamos de ressaltar que o estruturalismo concretiza-se como: (i) um fenômeno diversificado; (ii) um método; e (iii) um ponto de vista científico. Logo, a Linguística, a disciplina proposta pelo mestre genebrino, tornou-se a ciência-piloto para as humanidades, pois propunha um método rigoroso para o estudo da língua. Tanto foi assim que outras correntes teóricas se serviram da proposta saussuriana para estudar outros campos das ciências humanas, como, por exemplo: a Psicanálise lacaniana; a Antropologia lévistraussiana; a Filosofia foucaultiana, dentre outras. 0 que motivava essa influência eram três fatores principais, a saber: o alto grau de formalização, o rigor metodológico, o estabelecimento de regras próprias e a interdependência dessas regras.

Por exemplo, no caso de Barthes, a busca pelos fundamentos saussurianos é constante, como podemos apreender no seguinte trecho:

Efetivamente, como estudo de uma fala, a mitologia é apenas um fragmento dessa vasta ciência dos signos que Saussure postulou há cerca de 40 anos sob o nome de semiologia. Esta ainda não se constituiu. No entanto, desde o próprio Saussure, e por vezes independentemente do seu trabalho, todo um setor da pesquisa contemporânea retoma incessantemente o problema da significação: a psicanálise, o estruturalismo, a psicologia eidética, algumas tentativas novas de crítica que Bachelard inaugurou pretendem estudar o fato apenas na medida em que ele significa. Ora, postular uma significação é recorrer à semiologia. Não quero dizer com isso que a semiologia cubra igualmente todas essas pesquisas: elas têm conteúdos diferentes, mas têm um estatuto comum, sendo todas elas ciências dos valores; não se contentam em circunscrever o fato: definem-no e exploram-no como um valor de equivalência (BARTHES, 2003, p. 201). 
Nessa passagem barthesiana, podemos apreender com primazia a postura teórica adotada pelo semiólogo em sua leitura da obra saussuriana. Como destaca Nova (2009, p. 32), Barthes traz um novo olhar para os estudos da língua(gem): "Esse novo olhar sobre o signo leva a marca de outro trabalho de texto, diferentemente do que vinha sendo feito pela crítica, pela hermenêutica. Não se tratava de buscar os sentido correto, único, mas a sua pluralidade". Eis a perspectiva privilegiada pela leitura barthesiana: "a ruptura de todo e qualquer sistema de servidão, a língua, como sistema de valores, constitui, segundo esse autor [Barthes], uma ideologia opressora. Não há diferença entre linguagem e ideologia" (NOVA, 2009, p. 32). Por isso, para Barthes (2003), a semiologia não é uma ciência que cobre as outras, mas as ampara, porque serve como estatuto comum para elas.

Outro fato que constata a busca dos princípios saussurianos e sua difusão nos estudos da linguagem, sobremaneira naqueles que investiram na análise do texto e do discurso, foi a publicação do número 8 da revista francesa Communications, em 1966. Essa edição tinha como título L'analyse structurale du récit, e nela publicaram Greimas, Bremond, Todorov, Barthes, entre outros. Esses autores se reuniram nessa edição com o intuito de estabelecer, cada qual a seu modo, as ferramentas e os métodos para uma análise estrutural da narrativa. De acordo com Fiorin (1999) e Broden (2011), essa edição consagrou a análise estrutural da narrativa, mostrando-se, além disso, como prova efetiva de que Barthes e Greimas estavam inseridos, naquele momento histórico-social e cultural, na mesma corrente de pensamento e que, a partir dela, fundamentaram cada um o seu percurso nas ciências humanas e da linguagem.

\section{Estudos semióticos e semiológicos: as semelhanças e as diferenças}

Não temos uma Semiótica, mas Semióticas, porque há diferentes linhas teóricas em curso. Embora não sejam excludentes, elas são diferentes, conforme explicam Coelho, Costa e Fontanari (2016). Para citar as Semióticas mais representativas no cenário brasileiro, existe a Semiótica fundada pelo americano Charles Sanders Pierce (1839-1914) a qual, de acordo com Santaella (1983), possui um substrato filosófico denso que a caracteriza como uma ciência geral e abstrata. Temos, também, a Semiótica da Escola de Moscou, que se estrutura a 
partir dos estudos de Lotman (1996) e Propp (1984). Essa vertente investiga as inter-relações das esferas da cultura, da história e da literatura, sobretudo. A semiótica narrativa e discursiva, proposta pelo estudo de Greimas e Courtés (2008), é outra expoente. Ela se interessa pelo estudo do parecer do sentido a partir da descrição da semiose dos textos (COELHO, COSTA, FONTANARI, 2016).

Barthes, por sua vez, propõe uma semiologia. Como um pensador do mundo contemporâneo, intensamente devotado à interpretação de seus signos verbais e imagéticos, ele entendeu a crítica como arte da palavra em pé de igualdade com a literatura e, portanto, preferiu o termo semiologia, como explicam Coelho, Costa e Fontanari (2016). Motta (2012) e Mounin (1970), por sua vez, esclarecem que o embate com os signos e suas astúcias terminou por fazer dele um filósofo de índole ceticista, posição que, aliás, ele mesmo reivindicou em sua última fase.

Diante desse contraste de posicionamento, cabe distinguirmos Semiologia de Semiótica nos estudos ditos do discurso e do texto. A Semiologia elucida as leis que organizam os signos, portanto, nas palavras de Barthes (2003, p. 203),

[...] é preciso não esquecer que, contrariamente ao que se sucede na linguagem comum, a qual me diz simplesmente que o significante exprime o significado, devem-se considerar em todo o sistema semiólogo não apenas dois, mas três termos diferentes; pois o que se apreender não é absolutamente um termo, um após o outro, mas a correlação que os une: temos, portanto, o significante, o significado e o signo, que é o total associativo dos dois primeiros termos.

Já a Semiótica de linha francesa empenha-se em constituir uma disciplina que possa dar conta dos efeitos de sentido dos objetos. Para isso, ela faz o seguinte recorte teórico-metodológico:

É claro que a definição corrente de semiótica como "sistema de signos" não convém ao sentido, porque pressupõe já o reconhecimento dos signos: substituindo-a por "sistema de significações", introduzir-se-ia já o conceito menos comprometido "significação"; substituindo, por fim, "sistema" - que é uma noção teórica, precisa e limitada - [por] conjunto, pode-se propor por definir, num primeiro momento, semiótica como um conjunto significante que se suspeita, a título de hipótese, possua uma organização, uma articulação interna autônoma. Dir-se-ia, também, que todo conjunto significante, desde o instante em que se pensa em submetê-lo à análise, pode ser designado como uma semióticaobjeto [...]. Os conceitos de conjunto significante e de semiótica-objeto não são, aliás, coextensivos um ao outro: os resultados da análise mostrarão, por vezes, que só uma parte do conjunto significante está coberta pela semiótica construída ou que, pelo contrário, esta explica mais grandezas do que as inicialmente previstas como parte do conjunto significante (GREIMAS; COURTÉS, 2008, p. 448). 
Logo, temos dois modos de apreensão do objeto do conhecimento. De um lado, Barthes parte de um prisma interpretativo do signo; daí seu interesse pelo terceiro termo: o signo. De outro, Greimas enfatiza uma diretriz descritivista dos procedimentos de produção do sentido; por isso, sua insistência na formalização de um conjunto significante organizando uma semiótica-objeto. Diante dessas propostas, podemos dizer que, embora as perspectivas de ambos sejam de caráter dedutivo, esses teóricos escolheram maneiras diferentes de abordar o sentido nos textos-objetos.

Além disso, embora existam diferenças entre esses dois pensadores, também há semelhanças que os emparelham. Tanto Barthes quanto Greimas estavam interessados em desvelar mecanismos subjacentes da produção do sentido. Em outras palavras, os estudiosos de linha estruturalista estavam nas décadas de 1950-1960 buscando estabelecer modelos teóricos que pudessem predizer as estruturas mais complexas e concretas a partir da apreensão das estruturas mais abstratas e profundas dos textos-objetos. É por isso que Barthes (1996, p. 8), por exemplo, assevera que, mesmo que exista "um abismo entre o aleatório mais complexo e a combinatória mais simples, ninguém pode combinar (produzir) uma narrativa sem se referir a um sistema implícito de unidades e de regras".

Greimas (1975) e Barthes (1996) concordam que para validar esse modelo teórico que possa capturar os elementos abstratos e simples e, a partir deles, apreender os componentes mais concretos e complexos dos textos-objetos, é necessário seguir uma via dedutiva constituída de uma proposta hipotética de descrição dos signos. Sendo assim, a investida na base saussuriana, em ambos os autores, é evidente e sempre asseverada e desenvolvida, cada uma à sua maneira. Por isso, Barthes (1996, p. 8) sustenta que: "o analista está quase na mesma situação que Saussure, diante da linguagem mais heteróclita, buscando destacar de uma aparente anarquia das mensagens um princípio classificatório e um foco de descrição"; e Greimas (1975, p. 8), por sua vez, "pensou-se então, pensa-se ainda hoje, que se pode sair desta dificuldade [busca do sentido] afirmando, partindo de Saussure, que as palavras não têm sentido, que existem apenas oposições, relações que dão certa aparência de sentido aos termos que articulam". Ambos procuram a base saussuriana, seja para validar seu ponto de vista, como no trecho barthesiano, 
seja para discordar e desenvolver sua própria proposta, como no trecho greimasiano destacado.

Além desses embates e alianças com a proposta saussuriana, Barthes e Greimas foram pensadores que desenvolveram suas teorias ao longo de suas publicações. No caso de Barthes, podemos depreender pelo menos duas principais tendências intelectuais. Numa primeira fase, ele foi muito influenciado pela vertente saussuriana e, com ela, desenvolveu a semiologia como método de análise de textos, buscando, assim, dar continuidade ao projeto do mestre genebrino. Numa segunda fase, Barthes foi expressivamente entusiasmado pelas propostas de Sartre. Nesse momento, podemos apreender que o sistema semiológico tornou-se um método interpretativo mais aplicado aos contornos sociais e, por isso, o signo linguístico foi associado à ideologia, um nutrindo o sentido do outro. A primeira fase barthesiana pode ser observada na obra Elementos de semiologia (BARTHES, 1996), e a segunda, na obra Mitologias (BARTHES, 2003), por exemplo.

Greimas também possui fases em seu desenvolvimento teóricometodológico. Podemos apreender pelo menos três delas. Na primeira, ele estava interessado na narratividade dos textos e nos desdobramentos da proposta das funções proppianas. O livro mais significativo dessa fase é a obra Semântica estrutural (GREIMAS, 1973). A segunda fase é um momento de difusão e desenvolvimento do escopo do projeto semiótico. Nesse momento, o pesquisador lituano possui uma equipe de pesquisadores que desenvolvem de maneira coordenada os níveis do percurso gerativo do sentido: nível profundo, narrativo e discursivo. O resultado desse desenvolvimento pode ser consultado na obra Dicionário de semiótica (GREIMAS; COURTÉS, 2008). Na terceira fase, Greimas explora as "caixas pretas" da teoria semiótica, isto é, desenvolve o programa narrativo para além dos objetos entesouráveis, perscrutando as continuidades e descontinuidades de um sentido. Ele publica nesse período as suas duas últimas obras: Semiótica das paixões, em coautoria com Fontanille (1993), e Da imperfeição (GREIMAS, 2002). A primeira obra investiga os campos do sensível na narratividade dos sujeitos, e a segunda, as rupturas estésicas dos objetos estéticos.

Observando essas características todas, podemos formular dois quadros comparativos: um com as semelhanças desses dois pensadores; outro, com as diferenças. Esses quadros, apresentamos respectivamente a seguir: 
As semelhanças entre Greimas e Barthes

\begin{tabular}{|l|l|l|}
\hline \multicolumn{1}{|c|}{ Semelhanças } & Barthes \\
\hline \multicolumn{1}{|c|}{ Pensadores } & Greimas & \multicolumn{2}{c|}{ Estruturalismo } \\
\hline $\begin{array}{l}\text { Conceituação } \\
\text { pensamente de }\end{array}$ & \multicolumn{2}{c|}{ Transfrástico } \\
\hline Nível da Língua & \multicolumn{2}{c|}{. } \\
\hline
\end{tabular}

Quadro 1. Fonte: Quadro criado pelos autores.

As diferenças entre Greimas e Barthes

\begin{tabular}{|c|c|c|}
\hline \multicolumn{3}{|c|}{ Diferenças } \\
\hline $\begin{array}{l}\text { Pensador } \\
\text { Conceituação }\end{array}$ & Greimas & Barthes \\
\hline $\begin{array}{l}\text { Denominação da } \\
\text { disciplina }\end{array}$ & Semiótica & Semiologia \\
\hline Signo & $\begin{array}{l}\text { (i) Plano do conteúdo } \\
\text { (ii) Plano da expressão }\end{array}$ & $\begin{array}{l}\text { (i) significante } \\
\text { (ii) significado } \\
\text { (ii) signo }\end{array}$ \\
\hline \multirow{3}{*}{$\begin{array}{l}\text { Desenvolvimento da } \\
\text { teoria }\end{array}$} & (i) narratividade dos textos & $\begin{array}{l}\text { (i) método de análise } \\
\text { de textos de caráter } \\
\text { mais estruturalista }\end{array}$ \\
\hline & $\begin{array}{l}\text { (ii) desenvolvimento dos } \\
\text { níveis do percurso gerativo } \\
\text { do sentido }\end{array}$ & \multirow{2}{*}{$\begin{array}{l}\text { (ii) método } \\
\text { interpretativo mais } \\
\text { aplicado aos contornos } \\
\text { sociais }\end{array}$} \\
\hline & $\begin{array}{l}\text { (iii) desdobramentos } \\
\text { teóricos para além e aquém } \\
\text { do percurso gerativo de } \\
\text { sentido }\end{array}$ & \\
\hline
\end{tabular}

Quadro 2. Fonte: Quadro criado pelos autores.

Para além desses quadros, compreendemos que entre Barthes e Greimas existem inúmeras e diversas relações, umas mais explícitas, outras menos. No entanto, o que esses dois quadros expõem é que há tanto semelhanças patentes, quanto divergências teóricas evidentes entre eles. Sendo assim, no panorama que resgatamos, pautamo-nos nos principais pontos que enlaçam e desatam esses dois grandes pensadores do século XX.

Por isso, ressaltamos que, embora a Semiótica e a Semiologia possuam muitas correlações devido ao seu fundo estruturalista, é necessário sempre enfatizar a autonomia dessas duas disciplinas. Cada uma delas seguiu e segue um percurso independente. Todavia, não podemos também deixar de dizer que tanto Barthes quanto Greimas fizeram - e continuam fazendo - parte de um fenômeno ainda em curso: a busca pelo sentido. Eis o que os une e os separa. Logo, o objetivo é o mesmo, o modo de fazê-lo, não. 


\section{Considerações finais}

Existem várias e diferentes teorias que se debruçam sobre o sentido nos diversos campos das humanidades, desde a Lógica Formal até as teorias da Cibernética. Neste artigo, nosso intuito foi o de abordar dois dos maiores contribuintes dos estudos estruturalistas nas ciências humanas e da linguagem: Barthes e Greimas. Para tanto, rastreamos as principais convergências e divergências que reúnem e separam esses dois pensadores.

Tanto a Semiologia de Barthes, quanto a Semiótica discursiva de Greimas, constituíram disciplina e angariaram seguidores por todo o mundo. É claro que eles não foram os únicos a terem seus nomes propagados no contexto intelectual borbulhante da segunda metade do século XX no que se refere aos estudos do texto e do discurso. Dentre as diferentes perspectivas teóricas emergentes naquele período, podemos citar os estudos de Maingueneau (2004), Foucault (1997), Pêcheux (1995), van Dijk (1997), Ducrot (1987), dentre outros. De forma geral, o espírito do tempo, Zeitgeist, era favorável às formulações científicas que exploravam o sentido para além das propostas lógicas e matemáticas de uma semântica formal. Todavia, isso não tira o mérito nem desmerece o fascinante legado desses pensadores que desenvolveram, cada um à sua maneira, as balizas saussurianas, bem como as desdobraram para campos científicos nunca antes desbravados.

Desse modo, observamos que a Semiótica greimasiana e a Semiologia barthesiana se separam, paulatinamente, da Semiologia saussuriana, pois elas, ao incorporarem o conceito saussuriano de valor e desenvolverem muitas das premissas hjelmslevianas, tornaram-se teorias com finalidades e métodos bem distintos. A Semiologia barthesiana buscou compreender os sistemas de significação, uma vez que o terceiro termo - isto é, o signo - "é o único a apresentar de uma maneira plena e suficiente, e que é efetivamente consumido" (BARTHES, 2003, p. 212), lembrando que ele é a associação do significante com o significado. A Semiótica, por sua vez, tem por escopo descrever a produção e a compreensão do sentido. Por conseguinte, nenhuma das duas é efetivamente uma teoria do signo, embora estudem os signos no seio da vida social, como previa Saussure (2013). 
Isso comprova mais uma vez que tanto Barthes quanto Greimas foram grandes pensadores que desenvolveram as propostas de Saussure. No caso de Barthes, por exemplo, ele possui duas grandes rupturas: uma com o modelo saussuriano e outra com o modelo estruturalista. Como já dissemos, ao invés de reiterar a equivalência saussuriana de um significante com um significado, Barthes mostra que são três os termos de um sistema semiólogo (significante, significado e signo). Com o movimento estruturalista, ele se preocupa não somente com a forma de comunicação, mas também com o seu conteúdo; logo, adotando esse posicionamento, o pensador francês rompe com o propósito inicial do estruturalismo formal tal qual proposto, por exemplo, nos primeiros estudos de Lévi-Strauss, dado que Barthes não busca apenas estudar formalisticamente a comunicação. Por isso Barthes $(2003 ; 2004)$ joga luz sobre a ideologia do signo ao tratar a pequenas mitologia do nosso cotidiano.

O caminho da semiótica também vai para além e aquém das propostas saussurianas e hjelmslevianas. A começar propondo uma semântica gerativa, geral e discursiva, a semiótica já define uma epistemologia diferente para seus estudos ulteriores. Depois, quando a teoria semiótica passa pela constituição do percurso gerativo de sentido; e, em seguida, pela sua complexificação, com o estudo, no nível narrativo, das modalidades do fazer e do ser e o estudo das paixões e, atualmente, nos desdobramentos do nível tensivo; temos, com certeza, uma disciplina muito distinta daquela planejada no Curso de linguística geral. Desse modo, embora as bases saussurianas e hjelmslevianas ainda sejam constituintes inalienáveis do projeto semiótico, elas foram radicalmente desdobradas por Greimas e seus discípulos.

A Semiologia é definida no Curso de linguística geral como uma ciência que investiga "a vida dos signos no seio da vida social" (SAUSSURE, 2013, p. 24). Barthes e Greimas leram essa definição e, a partir dela e com ela, construíram, cada um a seu modo, uma disciplina geral, coerente e predicativa no seio das ciências humanas e da linguagem. Por isso, embora possuam semelhanças e diferenças entre si, sempre poderão ser lembrados como aqueles que vislumbraram a possibilidade que outrora era entendida como impossível: descortinar o sentido em seus mais variados matizes e formas a partir de uma perspectiva científica. 


\section{Referências}

BARTHES, Roland. Le système de la mode. Paris: Seuil, 1967.

Elementos de semiologia. São Paulo: Cultrix, 1996.

. Mitologias. São Paulo: Difel, 2003.

. 0 grau zero da escrita. São Paulo: Martins Fontes, 2004.

BRODEN, Thomas Falköping. The evolution of french linguistics after the war: A. J. Greimas conversion to "saussurism". Texto! July 1998 [on-line]. Disponível em: <http://www.revue-texto.net/Inedits/Broden_Evolution.html>. Acessado em: 02 dez. 2018.

Toward a Biography of Algirdas Julius Greimas (1917-1992). Lithuanian Quarterly Journal of Arts and Sciences. Editor of this issue Patrick Chura. v. 57, n. 4. 2011. Disponível em: <http://www.lituanus.org/2011/11_4_01Broden.html>. Acessado em: 02 dez. 2018.

COELHO, Patrícia Margarida Farias; COSTA, Marcos Rogério Martins; FONTANARI, Rodrigo. O parecer do sentido: a perspectiva da semiótica. Razón y Palabra. v. 20, n. 1, p. 1-18, mar. 2016. Disponível em: < http://www.revistarazonypalabra.org/ index.php/ryp/article/view/234>. Acessado em: 02 dez. 2018.

DIJK, Teun van. Discourse as social interaction. London: Sage, 1997.

DOSSE, François. História do estruturalismo. v. 1: o Campo do signo - 19451966. São Paulo; Campinas: Ensaio; Unicamp, 1993.

DUCROT, Oswald. 0 dizer e o dito. Tradução de Eduardo Guimarães. Campinas: Pontes, 1987.

FIORIN, José Luiz. Sendas e veredas da semiótica narrativa e discursiva. Revista Delta, v. 15 n.1, São Paulo fev./jul. 1999. Disponível em: <http://www.scielo.br/ scielo.php?script=sci_arttext\&pid=S0102-44501999000100009>. Acessado em: 02 dez. 2018.

0 projeto hjelmsleviano e a semiótica francesa. Galáxia: revista transdisciplinar de comunicação, semiótica, cultura. São Paulo, v. 5, p. 19-52, 2003.

FOUCAULT, Michel. A ordem do discurso. Aula inaugural no Collège de France, pronunciada em 2 de dezembro de 1970. Tradução de Laura Fraga de Almeida Sampaio. Lisboa: Relógio D'água Editores, 1997.

GREIMAS, Algirdas Julien. Semântica estrutural. Tradução de H. Osakape e I. Blikstein. São Paulo: Cultrix/EDUSP, 1973.

. Sobre o sentido: ensaios semióticos. Tradução de Ana Cristina Cruz Cezar et al. Petrópolis: Vozes, 1975.

2002.

Da imperfeição. Tradução de Ana Claudia de Oliveira. São Paulo: Hacker,

GREIMAS, Algirdas Julien; COURTÉS, Joseph. Dicionário de semiótica. Tradução de Alceu Dias et al. São Paulo: Contexto, 2008.

GREIMAS, Algirdas Julien; FONTANILLE, Jacques. Semiótica das paixões: dos estados de coisas aos estados de alma. Tradução de Maria José R. Coracini. São Paulo: Ática, 1993. 
HJELMSLEV, Louis. Prolegômenos a uma teoria da linguagem. Tradução de J. Teixeira Coelho Netto. São Paulo: Perspectiva, 2009.

LOTMAN, Yuri. La semiosfera. Tradução de Desidério Navarro. Madrid: Ediciones Cátedra, 1996.

MAINGUENEAU, Dominique. Análise de textos de comunicação. Tradução de Cecília P. de Souza-e-Silva e Décio Rocha. 3. ed. São Paulo: Cortez, 2004.

MOTTA, Leda Tenório. Roland Barthes - uma biografia intelectual. São Paulo: Iluminuras; Fapesp, 2012.

MOUNIN, Georges. Introduction à la sémiologie. Paris: Minuit, 1970.

NOVA, Vera Casa. Roland Barthes: a semiologia in extremis. In: PINTO, J.; NOVA, V. C. Algumas semióticas. Belo Horizonte: Autêntica Editora, 2009, p. 31-34.

NOVA, Vera Casa; PAULINO, Graça. Introdução à semiótica. In: PINTO, J.; NOVA, V. C. Algumas semióticas. Belo Horizonte: Autêntica Editora, 2009, p. 7-31.

PÊCHEUX, Michel. Semântica e discurso: uma crítica à afirmação do óbvio. Tradução de Eni Pucinelli Orlandi, Lourenço Chacon J. Filho, Manoel Luiz Gonçalves Corrêa e Silvana M. Serrani. Campinas: Unicamp, 1995.

PROPP, Vladimir. Morfologia do conto maravilhoso. Tradução de Jasna Paravich Sarhan. Rio de Janeiro: Forense Universitária, 1984.

SAUSSURE, Ferdinand de. Écrits de linguistique génerale. Textos estabelecidos e editados por Simon Bouquet e Rudolf Engler com a colaboração de Antoine Weil. Paris: Galimard, 2002.

Curso de linguística geral. Tradução de Antônio Chelini, José Paulo Paes e Izidoro Blikstein. 28. ed. 1. reimpressão. São Paulo: Cultrix, 2013.

SANTAELLA, Lúcia. 0 que é semiótica. São Paulo: Brasiliense, 1983. 